\title{
Production Digitalisation in Medium IT- Companies: Through the Example of Order Book
}

\author{
Chalova M.V.* \\ Limited Liability Company «GELIOS-S» \\ Kostroma, Russia \\ e-mail: geliosm@yandex.ru
}

\author{
Bragina Z.V. \\ Kostroma State University \\ Kostroma, Russia \\ e-mail: bragzv@yandex.ru
}

No stocks of energy or intellect can push a company
to a higher level unless it bows to HRM Digit.
Mozhenkov Vladimir [1: 124]

\begin{abstract}
The paper describes a solution to a major challenge: development of methodological approaches to production digitalisation in medium-sized IT-companies by using the example of making an order book for IT-projects based on the resource approach and the value chain concept. The authors consider an IT-company as an independent economic agent, for which cost cuts on the production of IT-projects is of vital importance. The paper analyses the market of digital technologies and identifies features of medium IT-companies, namely a wide variety in the cost of IT-projects and the qualification levels of employees, which makes the optimization of the order book more challenging. The authors suggest classifying various projects by their technological similarity and labour input. Three distinctive groups of projects are identified: simple, moderately difficult and difficult. The authors classified the costs of an IT-company by the benefits and the method of its calculation that take into consideration the IFRS as well as specific features of production peculiarities in IT-companies. For this, the authors studied the working time of administrative and managerial divisions. Activities of their employees in medium-IT companies are not monitored automatically. For each projects, direct labour costs of administrative and customer-oriented activities were identified. The authors suggest a model of order book optimization, the target function of which is the revenue from IT-projects. The problem limitations (bi) are presented by factual resources that illustrate the production potential of a medium IT-company and its organizational and financial features. To provide for the applied use of the mathematical formulation of the problem, two formal requirements were met in the methodology of its development: the formulation was made according to the requirements set in GOST $P$ 54870-2011; the model uses information stored in the information space on the 1C: Enterprise (1C: Predpriyatiye) platform.
\end{abstract}

Keywords - planning, order book, medium IT-company, ITproject, chain of benefit, optimization model.

\section{INTRODUCTION}

According to the data of International Data Corporation (IDC), that specializes in the research of the IT-market, the world software market grew by $5.5 \%$ in 2016, which exceeds the figure for 2015 by $1.2 \%$, thus reaching the total volume of $\$ 369$ bln. The reasons lie in the recovery of the Eurozone economy and the growth in the USA [2]. Yelena
Semenovskaya, IDC Director for Research for Russia and the CIS) speaking at the MERLION IT Solutions Summit 2019 said: 'We are happy to say that the Russian IT-market followed the world trend in 2018 and increased by almost $18 \%$, which is a record. Global factors, e.g. the replacement of hardware, played its role. However, it is digitalization, which IDC considers to be the driver [3].

The development of the IT-market in Russia is paid a lot of attention. The strategy of the IT-industry development for 2014-2020 and up to 2025 defines the industry in Russia as developing most dynamically [4]. For instance, in 2017 the share of the industry in the GDP was $0.88 \%$, while in 2025 it should reach $1.45 \%$, with the export of computer and information services expected to reach $\$ 8.3354 \mathrm{bln}$. The average growth rate of the Russian market in the last ten years has exceeded the world average; besides, the Russian ITindustry in the nearest 5-7 years has the potential for fast growth - by $10 \%$ a year and higher [5].

Most IT-companies in Russia can be described as small or medium, with 10-100 employees directly engaged in digitalization of production companies and organizations and oriented at the platform of a sole vendor. For example, there are over 200 IT-companies in St. Petersburg and Leningrad region alone that work on the technological platform $1 C$ : Enterprise [6].

According to the analysts of Pervy BIT, a company specializing in developing information systems on the platform of a Russian business-software developer 1C, out of 555 projects in the domestic market, $66 \%$ were completed by the set deadline or exceeded it by $10 \% .24 \%$ of projects went past the deadline by $11-30 \%, 10 \%$ of projects went past the deadline by more than $30 \% .78 \%$ of projects were within the budget or exceeded it by no more than $10 \% ; 19 \%$ of projects exceeded the budget by $11-30 \%$, and $3 \%$ of projects exceeded the budget by more than $30 \%$ [7].

\section{TARGET SETTING}

The market of digital technologies is characterized by a large capacity; thus, prospects of IT-companies to find new contracts are realistic. Sufficiency of new orders for ITservices makes IT-companies carefully select and plan the 
order book taking into account limitations of the budget, performance time and resources. However, forming the order book is a mutual process. We would like to mention that Yakovleva made an absolutely right conclusion that orders to develop digital technologies can be limited by the customers' lack of finance, which prompts IT-companies seek for opportunities to cut costs of IT-projects [8].

Russian IT-companies new contracts are selected according to estimates and experience of the company's leading experts. It is not the most reliable method, because new contracts are highly complex and, therefore, require special trainings for users. One of the best-known Russian companies Konsalting po Upravleniyu IT (IT-Management Consulting) specializes in trainings for managers and experts of companies, using best national and foreign practices of business planning, and publishes many of its methodological guidelines. The company has developed and now uses a set of methods, aimed to manage the relations between ITcompanies and a variety of companies and organizations [9]. Their solutions help IT-companies to plan their development strategies and create new IT-products, required by or interesting to businesses. We would not want to diminish methodologies found in available research papers; however, we have failed to find any research where IT-companies are regarded as independent companies. As a rule, researchers, studying optimization of costs in an IT-business, look at it as related to customers' estimates, namely, percentage in the capital turnover, percentage of IT-employees in the customer's company; costs per one user of IT. Effectiveness reserves within the IT-company itself are even not taken into account [10].

Unlike A.Mikhailov's school, we consider an IT-company as an independent economic agent with one of the major costs being cost cuts on the production of IT-projects.

Process and projects planning lie at the core of theoretical papers on planning approaches in IT-companies, namely, forming their order books $[11,12]$. V.I. Lobanov suggests optimizing the list of projects to be included in the order book by modelling liner-programming problems. The regulatory base for the model is the labour input of the business activity. The applied methods include estimation of labour input and re-estimation at various project stages. The more detailed the estimation of business activities, the more precise the estimate of labour input at separate stages and of the project in general. However, such an approach does not enable to see the full picture of the operational activity in an IT-company and of the use of its resources.

We believe that medium IT-companies, while making their order books, should take into consideration not only the labour input and project stages of developing an IT-product, but also tangible costs, production renewal costs, quality of intellectual and other resources that are involved, directly or indirectly, in producing value for the customer. In other words, in medium companies it is important to look at the order book through the prism of the value structure of the project under consideration. The value of IT-projects is defined through both their objective features (the object of digitalization, the level of technical requirements, the completion period) and the readiness of the customer to digitize its economic and managerial activities.

\section{METHOD}

To provide for the applied use of the mathematical formulation of the problem, two formal requirements were met in the methodology of its development: the formulation was made according to the requirements set in GOST P 548702011. The practical use of the model of optimizing the order book requires constant monitoring of its major indicators as well as the channel of obtaining the most reliable managerial information. It can be reached if the model is based on sole information space, e.g. standard configurations of $1 C$ : Enterprise platform. It enables to unite operations performed to make in a variety of applied solutions into the single business-process without outsourced assistance and additional resources.

Let us start from the object of planning. Medium ITcompanies make projects with a wide range of contract process: from several thousand roubles to tens of millions. The number of contracts varies from several hundred to several thousand projects. Such a range is essential for further development. A medium IT-company grows from servicing similar companies of various activity types. It not only supports and maintains standard IT-solutions and their adaptation, but also develops new specialized industrial configurations on the existing platform and their use in production. In this way the company gains experience and selects staff, able to perform more complex and large-scale projects. Franchise is a major source of growth in an ITcompany. This form of economic activity shows trust in competency and reliability of a developing business and enables an IT-company to aspire to perform complex tasks.

Such a wide range of interests and opportunities of medium IT companies makes forming the order book more difficult. To digitize the order book making it is necessary to classify projects by their technical similarity. We have identified three groups of projects.

The first group includes projects that use standard functions of software without additional development and adaptations of their configuration. The company services include, as a rule, installation of a standard product, minimal training for employees, support and maintenance (provisional name: simple projects).

The second group includes products that are more specific: they require automation of industrial business processes. Such projects are based on standard software solutions that are developed further and adapted to a certain company. Such projects are performed by several IT-specialists (consultants, analysts, programmers, and technical staff). (provisional name: moderately difficult projects).

Projects of the third group involve the large-scale industrial use of the product. They are performed by a team of professionals headed by the project manager. Such projects include a succession of stages: evaluation, modelling, planning, development, testing, training, trial, industrial use. Such projects are performed on a large scale; they are more complex and sophisticated. Both standard configurations, 
adapted to the customer's specifics, and specially designed configurations "from scratch" on the single platform are used. (provisional name: difficult projects).

Optimization of the order book of an IT-company is done for each group separately. To make a model, we need to identify resources and other specific features of a medium ITcompany that limit its productive capacity. Intellectual labour is known to be the main resource of an IT-company - creative labour that is hard to measure in the common sense of the word. We assume that employees' labour creates value and added value that are usually measured in the monetary equivalent. Therefore, we can estimate production resources by using the value chain concept. Nowadays the cost estimation in IT-companies do not involve measuring the added value of the project. We have failed to find methods of such estimates in regulatory documents as well as research papers.

It prompted us to classify costs in an IT-company by added value to the IT-project. The core of the chain -ofvalue-for-customer concept is value; thus, it is reasonable to classify costs by adding value to an IT-project, namely:

a. costs that add value to the project from the customer's point of view: remuneration to programmers, analysts, consultants, technical staff,; purchase costs of software and ITS, refresher courses for IT-specialists and travel costs, remuneration of administrative and managerial staff of customer-oriented divisions of the company, payments to the Social Security Fund and insurance against accidents and occupational illnesses, hospitality expenses;

b. costs that, according to the customer, do not add value to the project, but are necessary in production (e.g. remuneration of administrative and managerial staff who perform administrative functions, their insurance and refresher courses, costs of maintenance and upgrade of the existing software, costs of information services, ISO-related costs, costs of investment into the company's development etc.);

c. costs that do not add value to the IT-project from the consumer's point of view and should be eliminated or reduced: expenses for the remuneration of employees of auxiliary departments and their insurance payments; costs of office maintenance; costs of the medical examination of the staff, postage, costs of advertising and site maintenance, marketing products, interest on loans, etc.

This cost classification provided by the management reporting forms will help IT-company managers to focus on reducing and eliminating costs that do not add value to the product from the consumer's point of view and are not justified from the production point of view. It, in turn, will contribute to the main goal of the business: to continuously increase value for the consumer and save costs on developing an IT-project.

We have developed a procedure for calculating costs of an IT company based on the value added to an IT project, taking into account the requirements of IFRS and the specific features of the production process of IT-companies.
The base of the procedure is the actual use of each employee's working time in each project. In medium-sized ITcompanies, as a rule, electronic records of the working hours of programmers, analysts, and consultants are kept, but the accounting of employees' working hours of administrative divisions is not automated. There is a need to conduct a study of the situation. Besides, the staff of administrative and management divisions combine customer-oriented and administrative activities. Therefore, when calculating the value chain of ongoing projects, it is necessary to investigate the use of employees' working time for each project. We conducted such a study using a work time log of a working day. For 30 days, we followed working hours of those employees, whose official duties included activities of customer-oriented and administrative nature. There were employees from four divisions of an IT firm: administration, customer service department, promotion and development centre, and accounting. The employees of these divisions recorded information on the work done in the work time log and indicated the type of work: administrative or client-oriented (indicating the project). All information from work time logs was compiled into a summary report for each unit, after which work time was identified for each type of work and project. Thus, data were obtained on the actual costs of working time for each employee engaged in a certain project.

The procedure we developed for calculating the value chain of an IT-project includes the following operations:

1. For each project $(j)$, the figures of direct costs $(i)$ are taken from the existing information system. Only these costs are taken that add value to the product $\left(a_{i j}\right)$.

2. For all indirect types of costs of the value chain, the total cost $\left(b_{i}\right)$ is also taken from the current information system.

3 . Indirect costs for the remuneration of the administrative staff, customer service department, promotion and development centre, and accounting departments are taken from the existing information system and classified by the purpose of work (customer-oriented and administrative) into certain types of costs according to the value stream in proportion to the actual working time defined during the research.

4. The share of each project $(j)$ in the total production of an IT-company within a year $\left(k_{j}\right)$ is calculated.

5 . The amount of each type of cost $(i)$ for each project $(j)$ is calculated $\left(a_{i j}=b_{i} * k_{j}\right)$.

6. The value chain of each project is calculated by type of cost $\sum_{i}^{m} a_{i j}=a_{j}$.

The analysis of the value chain calculation has helped to identify resources limiting the production capabilities of an ITcompany. By calculating the value chains of projects, it was found that the bulk of the costs is concentrated in complex projects. However, the proportion of costs varies significantly depending on the complexity of the project. Thus, labour costs vary from 42 to $58 \%$; expenses for materials and software from 3 to $30 \%$; development costs - from 7 to $17 \%$. Such a range in the demand for resources, required to perform projects of various complexity timely and duly, causes the risk 
of a shortage of current assets. The latter, in turn, can be smoothed out or eliminated through the optimization of the order book. The potential lack of current assets will be manifested, first, in a decrease in productivity of qualified project developers. The situation is complicated by the fact that the proportion of costs that do not add value to the service and can be reduced (i.e., a figurative "safety airbag") is only 3-4 \%. Therefore, planning the order book should ensure the equally distributed demand for all types of production resources, which contributes to the timely completion of projects and to maintaining the necessary level of the company's current assets. Costs that add project value to the customer and are necessary to ensure that the value is made reach $96 \%$. Reserves for reducing costs and, consequently, the cost of projects should be sought in saving time on project completion, in updating technology in an innovative way and in increasing the competence of developers. Therefore, when forming the order book, an IT company, should take into account the objectively necessary investments in innovative software products and advanced training of employees.

Optimization of the order portfolio for the planning period is presented as a model of a linear programming problem, Its solution enable to select IT-projects $\left(x_{1} ; x_{2} ; x_{3} \ldots x_{n}\right)$ with the highest income (revenue in roubles) taking into account limitations on the amount of resources and specific features of the production process, which determine the production potential of the company.

Let us consider the content and numerical values of the limitations of the problem model.

The first limitation in the model is the types of costs included in the first group of the IT-project value chain: salaries, accruals, material costs for the purchase of software and ITS; expenses for advanced training of IT-specialists, expenses for support and update of existing software, investment expenses. Limitations on such expenses are set at the level of the previous year, with the exception of the items provided for in the strategic development plan $\left(b_{i} ; i=1,2, \ldots 5\right)$. Limitations must be less than or equal to the set values.

The second limitation is the employees' labour input (in hours) according to the department: automation of budgetary institutions, wages, commercial enterprises and centres: development of projects and technical support. The numerical value $\left(b_{i}\right)$ is defined as the labour input in each department and is less than or equal to the maximum standard 120 hours per month $\left(b_{i} ; i=6,7, \ldots 10\right)$.

The third limitation is cash inflow by quarters of the planning period. To find the numerical value of the limitations of this group, we studied the structure of cash inflows by quarters over the past 10 years. The range of fluctuations in the quarterly volume of cash received for this period did not exceed $1.3 \%$, which enabled the following: $Q_{1}-18 \% ; Q_{2}-$ $33 \% ; Q_{3}-21 \%$ and $Q_{4}-28 \%$. Then the numerical values of the limitations are defined as the cash inflow under all contracts per quarter multiplied by its share (set percentage). The values for each $a_{i j}$ are defined in the same way as the share of funds coming from the customer in the corresponding quarter in the total project price $\left(b_{i} ; i=11,12 \ldots 14\right)$. Cash receipts must exceed or be equal to the set limit.
The fourth type. Making the order book, the IT-company prefers the projects from long-known partners whom specialists of the IT-company and the customers are already familiar with, and have already worked together. The projects of such priority partners must be included in the order book, which is shown in the model as more than or equal to $\left(b_{i}\right.$, where $\left.i=15\right)$.

\section{FINDINGS}

To verify the effectiveness of the proposed model for optimizing the order book of a medium IT- company, we tested it on the materials of 2018 medium-term projects of GELIOS-S, a medium IT-company, specializing in the automation of business processes in enterprises and using software products of $1 C$. To calculate the limitations of the problem, we used actual data; the completed IT- projects were regarded as variables. Besides, we also considered those projects that were discussed but were not included in the work schedule. Table I shows the results of the order book optimization for 2018 for a group of moderately difficult projects, expressed by the deviation of the numerical values of resource requirements in accordance with the optimal plan in comparison with the use of each resource in 2018.

TABLE I. RESULTS OF THE ORDER BOOK OPTIMIZATION

\begin{tabular}{|c|c|c|}
\hline No & Limitations in the problem model & $\begin{array}{c}\text { Deviation from } \\
\text { factual figures, } \\
\mathbf{2 0 1 8 , \%}\end{array}$ \\
\hline \multicolumn{3}{|c|}{ 1. From the project value chain of thousand RUR } \\
\hline 1.1 & Remuneration to IT-specialists & 0.97 \\
\hline 1.2 & $\begin{array}{l}\text { Tangible costs for software and ITS } \\
\text { purchase }\end{array}$ & 1.0 \\
\hline 1.3 & Training for IT-specialists & -1.02 \\
\hline 1.4 & $\begin{array}{l}\text { Costs of maintenance and update of } \\
\text { current software }\end{array}$ & 1.0 \\
\hline 1.5 & Investment in company development & 1.0 \\
\hline \multicolumn{3}{|c|}{ 2. Labour input according to the division, hours } \\
\hline 2.1 & $\begin{array}{l}\text { Department of automation for budgetary } \\
\text { institutions }\end{array}$ & 0.97 \\
\hline 2.2 & Department of payroll processing & 0.58 \\
\hline 2.3 & Department of software development & -3.47 \\
\hline 2.4 & Technical centre & -14.44 \\
\hline 2.5 & Department of automation for businesses & 1.65 \\
\hline \multicolumn{3}{|c|}{ 3. Cash inflow } \\
\hline 3.1 & Q1 $\left(18 \%\right.$ to calculate $\left.a_{i j}\right)$ & 0.8 \\
\hline 3.2 & Q2 $\left(33 \%\right.$ to calculate $\left.a_{i j}\right)$ & 0.64 \\
\hline 3.3 & Q3 $\left(21 \%\right.$ to calculate $\left.a_{i j}\right)$ & 0.78 \\
\hline 3.4 & Q4 $\left(28 \%\right.$ to calculate $\left.a_{i j}\right)$ & 0.76 \\
\hline \multicolumn{2}{|c|}{ 4. Priority contracts } & 0 \\
\hline \multicolumn{2}{|c|}{ 5. Number of contracts } & 0.9 \\
\hline
\end{tabular}

As it is seen from Table I, the demand for resources in the optimal plan variant was not exceeded, while the volume of revenue (income) in the optimal plan increased by $27 \%$. Three types of resources turned out to be redundant compared to 2018, which is worthy of attention. The analysis of the situation enabled to understand the cause of the redundancy, which was not obvious without solving this problem. Moderately difficult projects were mainly carried out by consultants and analysts. The adaptation of typical configurations to the specifics of the customer is insignificant: $10-15 \%$ of the total amount of work, which affects the labour input of the software development centre staff. Services for 
setting up computer hardware and server equipment for medium-sized projects are also used to a small extent, because their customers' staff includes system administrators and technical specialists. Accordingly, the share of the technical centre staff equals 5-10\% of the total work of IT-specialists. The remaining 85-75\% of the work falls on consultants and analysts who provide consultative and methodological support to users when working with $1 C$ : Enterprise software. Thus, we have identified the time reserve of qualified specialists, which should be used in developing of more complex, long-term projects.

\section{CONCLUSION}

The model of the order book optimization includes the data contained in the information space of the typical configurations of the 1C: Enterprise platform.

The 1C: Enterprise platform not only provides storage space for data used in the optimization of the order book, but also makes it possible to correctly organize work on ITprojects and include such an effective consumer-oriented tool as a value chain in everyday activity of ta company. Such a solution will to combine all operations into chains of interconnected actions, which will allow quick respond to changes in important data that affect the financial situation of the company. The result of the order book optimization will always be relevant and easily updated. At the same time, integration will ensure the correct calculation and analysis of the value chain in IT-projects, without resorting to employees' manual labour.

Thus, the integration of the suggested order book optimization model and the most popular domestic system of automation of economic and organizational activities $-1 \mathrm{C}$ : Enterprise - results in the following:

- calculation and adjustment of the company's order book can be regularly corrected;

- there is no time loss in work of administrative and managerial staff;

- the sequence of calculations will be clearly defined, which will eliminate the possibility of error in both the sequence of actions and the calculations.

However, the business success of medium IT-companies lies not only in optimizing their internal resources; the external environment also contains a significant potential for efficiency. That is why, for example, Kazmina I.V in her paper [13] shows how telecommunication technologies contribute to the increase in the efficiency of information technologies, which enables to develop their networks.

\section{References}

[1] V. Mozhenkov, Director's Gene. Seventeen Rules of Management a la Russia. Moscow; Mann, Ivanov i Ferber Publ., 2017, 256 p.

[2] IDC Home: The premier global market intelligence firm. [Electronic resource. Retrieved on February 28, 2020].

IT-market and digital transformation - IDC dat. How is the IT-market developing in Russia and in the world? CRN/RE ("IT-biznes") Publ. 2019. October 1. [Electronic resource. Retrieved on February 28, 2020].

[3] Regulation of the RF government of 1 November 2013, no. 2036-p (ed. October 18, 2018. On approval of the strategy of IT industry development in 2014-2015 and to 2025. Retrieved from: http://www.consultant.ru/document/cons_doc_LAW_154161/

[4] The development strategy of the IT-industry in Russia. [Electronic resource. Retrieved on February 28, 2020].

[5] The selection of qualified franchisees of 1C. [Electronic resource. Retrieved on February 28, 2020].

[6] Markets of It-services and IT-outsourcing in Russia. [Retrieved on February 28, 2020].

[7] E.A. Yakovleva, V.A. Zelikov, E.V. Titova, D.K. Kostina, E.A Gubertov, "Digitalization of the transport and logistics industry in the globalized world economy", Proc. of the Voronezh State Univer. of Engineer. Technol. vol. 81, no. 4, pp. 243-250, 2019.

[8] A.G. Mikhailov, "Cutting IT costs vs business", IT-strategies and the digital transformation in business. [Electronic resource. Retrieved on February 28, 2020].

[9] A.G. Mikhailov, "Business requirements to IT: what and how to plan for one year ahead, how to take into account the digital transformation of business in the company's IT-strategy", IT-strategies and the digital transformation in business. [Electronic resource. Retrieved on February $28,2020]$

[10] V.I. Lobanov, R.V. Sokolov, "Process planning of the order book in an IT-enterprise", Izv. Sankt-Peterburgskogo gosudarstv. Ekon. Univer. Publ., vol. 5, no. 101, pp. 55-59, 2016.

[11] V.I. Lobanov, R.V. Sokolov, "Process planning of the order book in an IT-enterprise: process approach", Nauchno-tekhnicheskie vedomosti Sankt-Peterburgskogo gosudarstv. Politekhnich. Univer. Ekon. nauki. Publ., vol. 3, no. 221, pp. 274-282, 2015.

I.V. Kazmina, "The main trends in the development of information and telecommunication technologies when creating high-tech products", Proc. of the Voronezh State Univer. of Engineer. Technol., vol. 81, no. 4, pp. 291-297, 2019. 